\title{
Contamination of Hospital Disinfectants with Pseudomonas Species
}

\author{
D. W. BURDON,* M.B., B.S. ; J. L. WHITBY, $\dagger$ M.B., M.R.C.P., M.C.PATH.
}

Brit. med. F., 1967, 2, 153-155

During the investigation of an outbreak of infection caused by Proteus mirabilis in the infants' nursery it was found that solutions of disinfectants in use there were contaminated with viable Gram-negative bacilli. The organisms cultured were not Proteus sp., and were quite unconnected with the outbreak. This finding prompted us to examine stocks of disinfectants in the hospital for the presence of living bacteria.

Subsequent investigation showed that aqueous solutions of Hibitane (chlorhexidine) and Savlon (cetrimide-chlorhexidine mixture in the ratio $10: 1$ ) issued from the pharmacy and in use throughout the hospital were frequently contaminated with organisms identified as Pseudomonas sp. The insidious nature of this contamination and its extensiveness seemed important enough to report, as such contamination may be more widespread than is generally supposed.

\section{Description of Investigation}

In the pharmacy batches of chlorhexidine and Savlon are made up in 100 - and 90 -litre quantities respectively by dilution of stock concentrate and then bottled in litre bottles. We sampled unopened and unused bottles of chlorhexidine $0.05 \%$ from one batch, and Savlon 1 in 30 (chlorhexidine $0.05 \%$ and cetrimide $0.5 \%$ ) from three batches. We also sampled residues in bottles returned from the wards from five batches of chlorhexidine $0.05 \%$ and five batches of Savlon 1 in 30 . All samples were found to be infected with Pseudomonas sp. The organisms found were not identical, and three distinct biochemical types were recognized, which we designated in relation to initial positive sample numbers as Ps. 10, Ps. 60, and Ps. 65. Ps. 10 was found in all the Savlon batches, and Ps. 60 and Ps. 65, but not Ps. 10, were found in chlorhexidine.

A search was made for the source of these organisms in the pharmacy, as the finding of positive cultures from unopened bottles suggested that contamination was most likely to be occurring there. Samples were taken from buik stock concentrates of disinfectant, distilled water, measuring-jars, mixing containers, the measuring-stick, polyethylene tubing, bottlefilling apparatus, shelves, benches, sinks, and bottle-washing apparatus. Though many different organisms were found in some of these sites, none having the characteristics of Ps. 10, Ps. 60 or Ps. 65 was recovered. Freshly prepared batches of chlorhexidine and Savlon were also tested immediately before bottling, and were found to be sterile. The bottle-washing apparatus was sampled before a batch of empty Savlon bottles was washed and was free of pseudomonads, but after contaminated bottles had been washed it was found to have become infected. Bottles contaminated with Ps. 10 were found to be still contaminated with that organism after washing, and an uncontaminated bottle washed immediately after a contaminated one was found to have become contaminated. We therefore concluded that infection was being maintained by the presence of a residual inoculum of bacteria in the bottles before they were refilled with fresh (sterile) disinfectant. In addition, washing contaminated bottles led to contamination of the washing

* Registrar in Clinical Pathology, United Birmingham Hospitals.

† Consultant Bacteriologist, Queen Elizabeth Hospital, Birmingham 15 apparatus, so that infection would subsequently be transferred to clean bottles.

The manufacturers of chlorhexidine and Savlon recommend that bottles should be thoroughly rinsed in tap-water, preferably hot, and then drained before refilling, and that isopropyl alcohol $4 \% \mathrm{v} / \mathrm{v}$ or ethyl alcohol $6 \% \mathrm{v} / \mathrm{v}$ should be added to the stock solutions once or twice a year to eliminate possible contaminating organisms. In our pharmacy the bottle-washing apparatus is connected to the cold-water supply, and before recommending that a change should be made to hot-water washing the survival of the Pseudomonas strains isolated was tested at higher temperatures. Two strains, Ps. 10 and Ps. 60, were tested and proved to be remarkably resistant to high temperature, though it was noted that cultures exposed to higher temperatures took much longer to grow, and that a high percentage of the initial inoculum was killed. Nevertheless, exposure to a temperature of $70^{\circ} \mathrm{C}$. for five minutes failed to sterilize the culture, and this implied that hot water could not be relied on to sterilize bottles before refilling.

All three strains were found to survive in chlorhexidine $0.05 \%$ freshly prepared in the laboratory, and Ps. 60 was also able to survive in $0.1 \%$ chlorhexidine. When Ps. 10 was inoculated into Savlon 1 in 30 dilution prepared in the laboratory it failed to survive, though it had been initially isolated from Savlon at this concentration. This is at present under further investigation. None of the strains was found to survive in $0.05 \%$ chlorhexidine containing $4 \% \mathrm{v} / \mathrm{v}$ isopropyl alcohol when tested in the laboratory, but recently a strain of Pseudomonas having the biochemical characteristics of Ps. 60 has been isolated from the residues in 3 out of 16 bottles which had been returned to the pharmacy after use. These bottles had contained $0.05 \%$ chlorhexidine and $4 \% \mathrm{v} / \mathrm{v}$ isopropyl alcohol. This latter finding indicates that continued use of isopropyl alcohol may ultimately select for strains resistant to both isopropyl alcohol and chlorhexidine, and thus that some other method such as autoclaving the returned bottles should be used to break the chain of infection, a conclusion reached by Lowbury (1951) in relation to bottles of cetrimide. Kelsey and Maurer (1966) reported contamination of returned ward stock bottles and freshly filled bottles of a white disinfectant fluid with a Klebsiella species. They too recommend disinfection of bottles before refilling.

Laboratory experiments to determine whether growth of the three strains of Pseudomonas would occur in Savlon and chlorhexidine were performed by inoculating $10 \mathrm{ml}$. of Savlon 1 in 30 with Ps. 10 , and $10 \mathrm{ml}$. of $0.05 \%$ chlorhexidine with Ps. 60 and Ps. 65 separately. The dilutions were made from stock concentrate with sterile distilled water in laboratory glassware. Inoculation was performed with a straight wire from a single colony of the respective organism grown on nutrient agar. Viable colony counts were performed at intervals during a period of four weeks by spreading $0.1-\mathrm{ml}$. volumes of an appropriate dilution on nutrient agar. Using this method we were able to demonstrate growth of Ps. 60 in $0.05 \%$ chlorhexidine, but not of Ps. 65 in $0.05 \%$ chlorhexidine or Ps. 10 in Savlon 1 in 30 . The viable colony count of Ps. 60 in $0.05 \%$ chlorhexidine showed a 100,000-fold increase during a period of three weeks. 


\section{General Characteristics of the Organisms}

The three strains of Pseudomonas, Ps. 10, Ps. 60, and Ps. 65, were all motile Gram-negative bacilli, oxidase- and catalasepositive, and produced nonpigmented colonies on nutrient agar. Glucose was utilized by oxidation. Growth on artificial media was characteristically slow, and the initial isolations from disinfectant solution required five to six days' incubation at room temperature before growth became apparent. Further cultural and biochemical properties are listed in Table I. In the biochemical and cultural tests we have performed Ps. 60 has the characteristics of Ps. multivorans, as described by Stanier, Palleroni, and Doudoroff (1966) except that, like three of their 19 strains, it failed to hydrolyse gelatin, and, like one of their strains, it failed to give an egg-yolk reaction. It is interesting that their strain 398, identified as Ps. multivorans, also lacked these two characteristics, and was one of the strains causing urinary infection in children described by Mitchell and Hayward (1966).

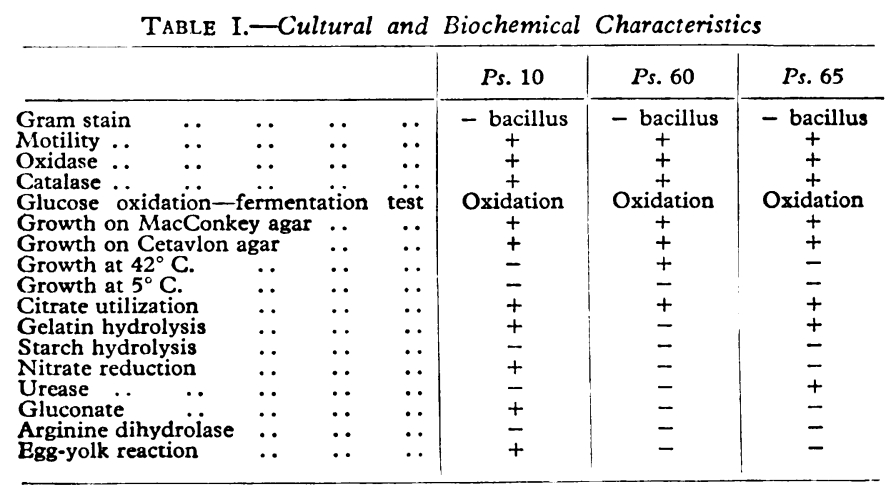

\section{Discussion}

The isolation of bacteria from chlorhexidine stock bottles has been recently recognized, and in 1965 the manufacturers (I.C.I.) issued a circular on the subject with recommendations for reducing the incidence of contamination. However, reports of contamination of chlorhexidine and of clinical infection caused by these contaminants appeared in 1966 . Mitchell and Hayward (1966) described seven cases of infection of the urinary tract in children after cystoscopy. The source of the infection was traced to the chlorhexidine solution used for disinfecting the bladder-irrigation reservoir. The infection was traced back further to the stock bottles of chlorhexidine $1 / 5,000$ in use in the hospital, and they concluded that the chlorhexidine solution had deteriorated on storage. Dulake and Kidd (1966) reported finding an organism most nearly identified as Alcaligenes faecalis from the urine of 30 gynaecological patients undergoing bladder drainage by indwelling catheter. The same organism was isolated from the jar used for storage of spigots after these had been sterilized by boiling. The jar contained $0.1 \%$ chlorhexidine.

In other reports of contamination of disinfectants with Pseudomonas species cork closures of bottles have at times been implicated. Lowbury (1951) concluded that contamination in bottles was being maintained by showers of bacteria from the cork. Anderson and Keynes (1958) concluded that the organisms did not actually survive in the disinfectant they were investigating (cetrimide) but that organisms were released from the cork when it was removed and thus passed out of the bottle with the disinfectant. Linton and George (1966) described a substance, probably a tannin present in cork (and tea), which is a very potent inactivator of chlorhexidine. They concluded that the neutralizing action of this substance was responsible for the contamination of chlorhexidine solution at Bristol. Cork closures have not been used in our pharmacy for several years, and all bottles tested in the present series had bakelite closures with rubber seals. If a neutralizing substance is involved in the contamination here described we have so far not been able to demonstrate it.

Clinical infections with these organisms have been described elsewhere. In our hospital we have looked for infection caused by Pseudomonas sp. other than Ps. aeruginosa in all urine and wound swabs received over a period of two months. For this purpose material was inoculated on to cetrimide agar (Lowbury and Collins, 1955) and after overnight incubation at $37^{\circ} \mathrm{C}$ keeping the plates at room temperature for a further four days. On no occasion were any of these strains isolated from urine, though Ps. 60 and Ps. 65 had both been isolated from jars of chlorhexidine used for disinfecting cystoscopes. From wound swabs several other Pseudomonas sp. were isolated, but they were all of biochemical types that were distinct from our strains Ps. 10, Ps. 60, and Ps. 65. However, disinfectants may well have been the source of these wound infections, as the disinfectant solution may have become contaminated after issue to the wards. Some support for this view is supplied by the isolation of $P$ s. putida and Aeromonas sp. in addition to Ps. 10 from a mop and a thermometer standing in Savlon 1 in 30 in the infants' nursery.

Another article better sterilized by other methods but commonly sterilized by chemicals is the cardiac catheter. We investigated two patients undergoing cardiac catheterization where the catheter used had been sterilized in Savlon 1 in 30. Ps. 10 was isolated from the Savlon solution employed for sterilization. Blood cultures were taken of venous blood from the right atrium via the catheter and of arterial blood from the brachial artery by means of a stainless-steel cannula that had been sterilized by autoclaving. Six cultures were taken in all, and Ps. 10 was isolated from each of them. We have not isolated Ps. 10 from blood cultures from suspected cases of bacterial endocarditis, but a serious potential threat obviously exists.

It is perhaps not generally appreciated how widespread contamination of chlorhexidine and Savlon solutions can become, so that ultimately all bottles of the aqueous solutions of these compounds may be contaminated at issue. To illustrate the extent of contamination Tables II and III record the isolations of Pseudomonas sp. from chlorhexidine and Savlon bottles issued by the pharmacy. Until the introduction of $4 \% \mathrm{v} / \mathrm{v}$ isopropyl alcohol all samples were contaminated. Since then very few isolations have so far occurred, but it seems possible that continued use of $4 \% \mathrm{v} / \mathrm{v}$ isopropyl alcohol may ultimately result in selection for strains resistant to chlorhexidine and $4 \%$ $\mathrm{v} / \mathrm{v}$ isopropyl alcohol. Later samples of all batches tested have been sterile; thus the possibility that some organisms may have taken a rather long time to be killed by the low concentration of the alcohol cannot be excluded.

Recently we have had the opportunity of sampling stock solutions of aqueous chlorhexidine and Savlon in four other

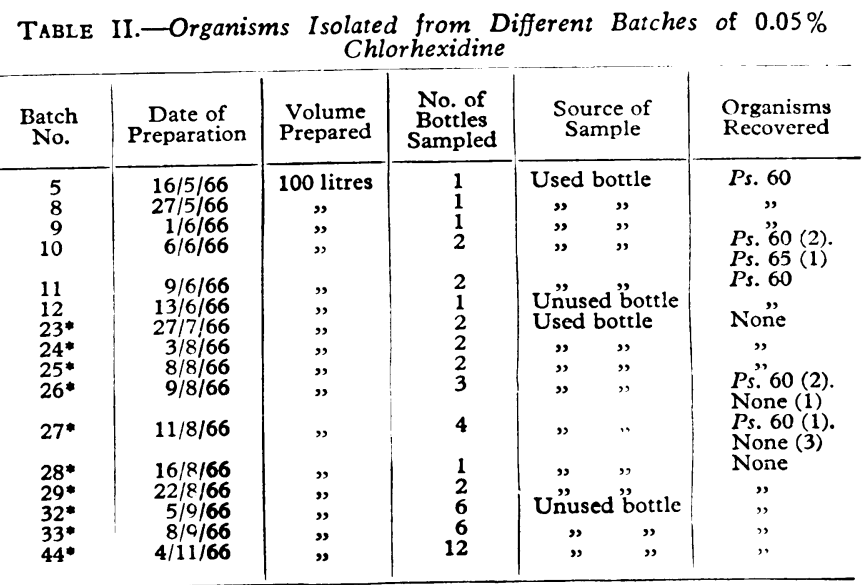

$4 \% \mathrm{v} / \mathrm{v}$ isopropyl alcohol added. 
hospitals. In all these hospitals organisms similar to those here reported were found; 30 out of the 48 samples taken yielded a growth of Pseudomonas sp. In one pharmacy the distilled

TABLE III.-Organisms Isolated from Different Batches of 1 in 30

\begin{tabular}{|c|c|c|c|c|c|}
\hline $\begin{array}{l}\text { Batch } \\
\text { No. }\end{array}$ & $\begin{array}{c}\text { Date of } \\
\text { Preparation }\end{array}$ & $\begin{array}{l}\text { Volume } \\
\text { Prepared }\end{array}$ & $\begin{array}{c}\text { No. of } \\
\text { Bottles } \\
\text { Sampled }\end{array}$ & $\begin{array}{l}\text { Source of } \\
\text { Sample }\end{array}$ & $\begin{array}{l}\text { Organisms } \\
\text { Recovered }\end{array}$ \\
\hline $\begin{array}{c}1 \\
2 \\
3 \\
3 \\
4 \\
4 \\
5 \\
14 \\
16^{*} \\
17^{*} \\
23^{*}\end{array}$ & $\begin{array}{r}3 / 5 / 66 \\
10 / 5 / 66 \\
20 / 5 / 66 \\
31 / 5 / 66 \\
7 \overline{7} \\
19 / 66 \\
2 / 8 / 66 \\
8 / 9 / 66 \\
31 / 10 / 66\end{array}$ & $\begin{array}{l}90 \text { litres } \\
\text { "’ } \\
90 \text { litres } \\
90 \text { litres } \\
45 \text { litres } \\
60 \text { litres } \\
\text { " } \\
"\end{array}$ & $\begin{array}{l}1 \\
2 \\
2 \\
1 \\
2 \\
1 \\
2 \\
1 \\
6 \\
6 \\
4\end{array}$ & $\begin{array}{l}\text { Used bottle } \\
\text { "” } \\
\text { Unused bैottle } \\
\text { Used bottle } \\
\text { Unused bottle } \\
\text { Used bottle } \\
\text { Unused bottle } \\
\text { " " } \\
", \\
"\end{array}$ & $\begin{array}{c}\text { Ps. } 10 \\
\text { ", } \\
, " \\
, \\
\text { ", } \\
\text { None } \\
\text { ", }\end{array}$ \\
\hline
\end{tabular}

$4 \% \mathrm{v} / \mathrm{v}$ isopropyl alcohol added.

water used for dilution was found to be heavily contaminated with the same organism found in samples of disinfectant distributed throughout the hospital.

Storage of distilled water presents a special problem, and we recommend that freshly distilled water, hot from the still, be used. But, this apart, it is important to decide what practicable steps can be taken to prevent contamination assuming significant proportions. If chlorhexidine solutions are sterile at the time of bottling sterilizing the bottles will at least ensure that supplies leave the pharmacy uncontaminated. If in addition $4 \% \mathrm{v} / \mathrm{v}$ isopropyl alcohol is added to aqueous preparations the chance of subsequent contamination on the wards will be very greatly reduced. Though these organisms are not highly pathogenic they are capable of causing human disease under certain circumstances, and unless steps are taken to rid stock solutions of this contamination further case reports can be confidently predicted.

\section{Summary}

Contamination of stocks of chlorhexidine and Savlon with Pseudomonas species resistant to the concentrations of chlorhexidine and Savlon in clinical use is reported. The contamination was maintained by a residual inoculum remaining in bottles after washing, and was spread to other bottles in the bottlewashing apparatus. It is suggested that some wound infections may be caused by disinfectants contaminated either at issue by the pharmacy or during use on the wards. The addition of $4 \% \mathrm{v} / \mathrm{v}$ isopropyl alcohol to aqueous preparations of both disinfectants was found greatly to reduce the incidence of contamination.

We gratefully acknowledge the help of the group pharmacist, $\mathrm{Mr}$. A. E. Marston, and other members of his staff throughout this investigation.

\section{REFERENCES}

Anderson, K., and Keynes, R. (1958). Brit. med. F., 2, 274.

Dulake, C., and Kidd, E. (1966). Lancet, 1, 980.

Kelsey, J. C., and Maurer, I. M. (1966). Mth. Bull. Minist. Hlth Lab. Serv., $25,180$.

Linton, K. B., and George, E. (1966). Lancet, 1, 1353.

[.owbury, E. J. L. (1951). Brit. F. industr. Med., 8, 22.

and Collins, A. (1955). F. clin. Path., 8, 47.

Mitchell, R. G., and Hayward, A. C. (1966). Lancet, 1, 793.

Stanier, R. Y., Palleroni, N. J., and Doudoroff, M. (1966). F. gen. Microbiol., 43, 159.

\section{Aorto-jejunal Fistula from Rupture of Teflon Graft, with Septic Emboli in the Skin}

\section{Brit. med. F., 1967, 2, 155-156}

We report the case of a patient who died from a massive haemorrhage into his gut from an aorto-jejunal fistula four and a half years after insertion of a plastic prosthesis of the abdominal aorta. It was the middle of the graft material itself that ruptured and not the suture line. A week before death showers of infected emboli appeared in the skin of the lower part of the body which were thought to be diagnostic of infective endarteritis of the graft.

\section{CASE HISTORY}

The patient, a tractor driver, was aged 38 when he presented with a four-year history of increasingly severe pain of the left side of his back and left thigh. There was no relevant past or family history of metabolic, vascular, or Marfan's disease. Clinical and radiological evidence of a large abdominal aortic aneurysm that did not involve the renal arteries was found. This was resected and a Tefion aorto-ileal bifurcation graft was inserted as an emergency operation by Mr. D. N. Ross at Guy's Hospital. The patient was started on anticoagulant therapy, which was continued for four and a half years. He was then admitted to Orpington Hospital on account of very severe haemorrhage from a radiologically demonstrable nonmalignant gastric ulcer, and anticoagulants were stopped. Four weeks later, only two days after discharge from hospital, the symptoms of his terminal illness developed: malaise, rigors, and aching in the body and head. The following week, in spite of systemic oxytetracycline, his condition worsened and he was readmitted to hospital, and on this day septic lesions appeared on the right heel, great toe, and sole of the foot, and he had signs of left lower-lobe pneumonia. Septicaemia secondary to his pneumonia was diagnosed (penicillin-resistant Staphylococcus aureus was cultured from the blood), and he was immediately started on treatment with cloxacillin, fusidic acid, and cephaloridine. On the ninth day of his illness "purpura" was noticed on his right thigh, and soon afterwards he developed bilateral femoral arterial occlusion. He was treated

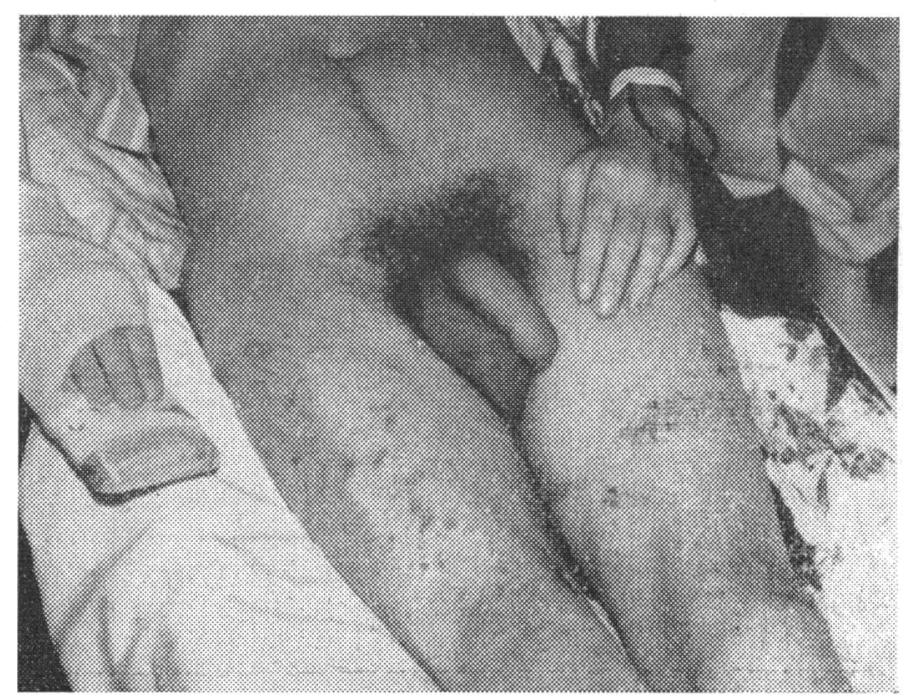

Septic embolic lesions on lower half of the body. Note the absence of splinter haemorrhages and finger-clubbing. 